\title{
Influence of Microstructure Evolution on the Coercive Forces in Low Silicon Non-Oriented Steels
}

\author{
I. Petryshynets ${ }^{a, *}$, F. KovaC ${ }^{a}$, V. Stoyka ${ }^{a}$ And J. Boruta ${ }^{b}$ \\ ${ }^{a}$ Institute of Materials Research, Slovak Academy of Sciences, Watsonova 47, 04353 Kosice, Slovak Republic \\ ${ }^{b}$ Material \& Metallurgical Research, Ltd., Pohranicní 693/31, 70602 Ostrava-Vitkovice, Czech Republic \\ The magnetic properties and their dependence on the peculiarity of microstructure in low silicon non-oriented \\ electrotechnical steels were studied in the present work. The estimation of dc magnetic properties of electrical \\ steels was carried out by measurements of coercive forces. It was shown that the coercive force change in silicon \\ steels is dependent on change of average grain size, crystallographic texture and homogeneity of microstructure of \\ the materials. It was revealed that the steels possessing columnar or huge grained microstructure had the lowest \\ measured values of coercive forces. The materials with such microstructure are characterized by a domination of \\ $(100)\langle 0 v w\rangle$ crystallographic orientation.
}

PACS numbers: 75.20.En, 74.25.Ha, 75.50.Bb, 75.50.Gg

\section{Introductions}

The NO electrotechnical steels belong to group of soft magnetic materials. The typical applications of NO steels are electromotors, generators etc. [1-3]. Constant attempts to improve the quality of electrical steels have quite naturally stimulated a search for corresponding improvements in the physical interpretation of magnetic losses $[4,5]$. High permeability and low iron loss have been particularly required in recent years in order to achieve higher efficiency and hence energy saving. Therefore it is important to control the final microstructure of these steels in terms of grain size and crystallographic texture [6]. Grain size optimization has attracted much attention and almost approached its limit by controlling chemical compositions and processing variables at each step [7]. Increasing grain size results in an increased domain size which initially results in a decrease in core loss because there are less domain walls to move. As domain size continues to increase, however, core loss begins to increase because the domain walls must move faster to cover the same distance [8].

\section{Experimental procedure}

As experimental material NO electrical steel $(\mathrm{F})$ was taken from industrial line after cold rolling reduction with $74 \%$ of deformation. Then this material was subjected to recrystallization annealing in laboratory conditions $\left(800^{\circ} \mathrm{C} / 10 \mathrm{~min}\right)$. The annealing atmosphere was pure hydrogen (dew point $\approx 23^{\circ} \mathrm{C}$ ). The chemical composition of the experimental material is presented in Table. The thickness of the investigated steel was $d=0.65 \mathrm{~mm}$. After recrystallization annealing, the mentioned steel was cold rolled in laboratory conditions. The value of experimental cold rolling reduction was conducted in range

\footnotetext{
* corresponding author; e-mail: ipetryshynets@imr.saske.sk
}

of $2 \%$ to $10 \%$. Then deformed samples were subjected to dynamical annealing in experimental furnace with heating rate of $V_{\mathrm{h}} \approx 20^{\circ} \mathrm{C} / \mathrm{s}$ and cooling rate of $V_{\mathrm{c}} \approx 5^{\circ} \mathrm{C} / \mathrm{s}$. Annealing temperatures were changed within the range of $850^{\circ} \mathrm{C}$ to $950^{\circ} \mathrm{C}$ for the annealing times of 2 and $5 \mathrm{~min}$. Chosen microstructure states were investigated to electron backscaterred diffraction (EBSD) analysis of crystallographic orientations of grains.

TABLE

Chemical composition of the investigated steel (in wt\%).

\begin{tabular}{c|c|c|c|c|c|c|c}
\hline \hline Material & $\mathrm{C}$ & $\mathrm{Mn}$ & $\mathrm{Si}$ & $\mathrm{P}$ & $\mathrm{S}$ & $\mathrm{Al}$ & $\mathrm{N}$ \\
\hline $\mathrm{F}$ & 0.006 & 0.24 & 1 & 0.07 & 0.009 & 0.013 & 0.011
\end{tabular}

The coercive force of the steel was measured by standard "Oersted type" coercive meter KPS-lC utilizing samples with the $3 \mathrm{~cm} \times 1 \mathrm{~cm}$ dimensions (long side was parallel to both rolling and external magnetic field directions).

\section{Results and discussion}

The microstructure evolution in the investigated $\mathrm{F}$ steel taken after annealing at different temperatures in dry hydrogen atmosphere is presented in Fig. 1. As one can see, the microstructure of the samples, annealed at $800^{\circ} \mathrm{C}$, is characterized by quite fine grains with average size varying in the range of $20-25 \mu \mathrm{m}$. In addition, the grains have homogeneous distribution on the cross-section of the thickness. In order to evaluate the magnetic properties of obtained samples the measurements of coercive forces were carried out. In case of mentioned samples the coercive force was $\approx 75 \mathrm{~A} / \mathrm{m}$.

The microstructure of experimental steels obtained after different thermomechanical treatments is presented in Figs. 1b-d. The presented microstructures were achieved during secondary recrystallisation process. It is well seen that grain boundary motion behavior strongly depends 


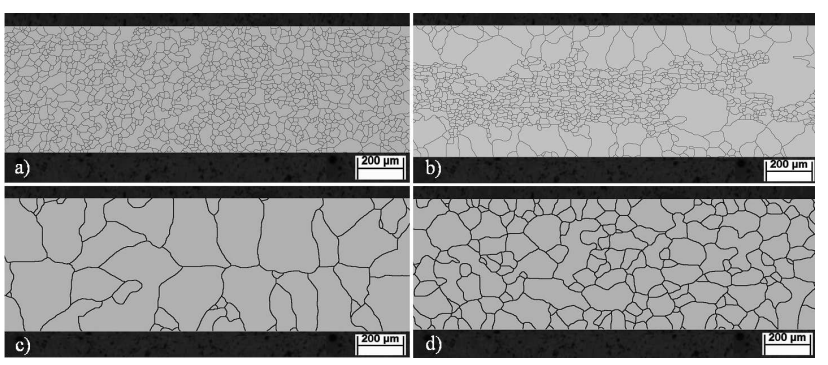

Fig. 1. Microstructure of $\mathrm{F}$ steel (a) annealed at $800{ }^{\circ} \mathrm{C} / 10 \mathrm{~min},(\mathrm{~b})$ with $6 \%$ of deformation annealed at $850{ }^{\circ} \mathrm{C}$ for 2 min., (c) with $2 \%$ of deformation annealed at $950{ }^{\circ} \mathrm{C}$ for $5 \mathrm{~min}$., (d) with $10 \%$ of deformation annealed at 950 for 5 min in dry hydrogen atmosphere.

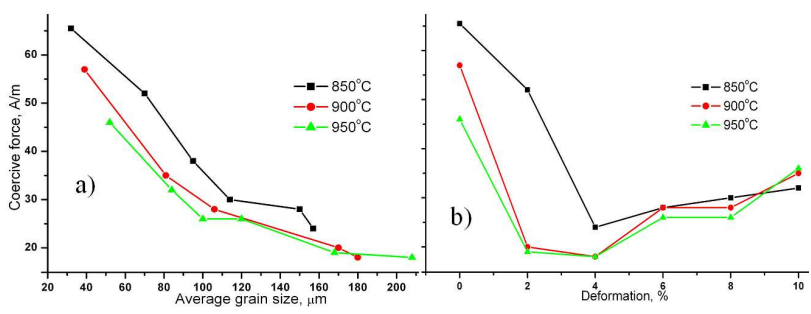

Fig. 2. Dependence of coercive force on (a) average grain size, (b) applied deformation in investigated $\mathrm{F}$ steel after annealing at $850^{\circ} \mathrm{C}, 900{ }^{\circ} \mathrm{C}$ and $950{ }^{\circ} \mathrm{C}$ for 5 min.

on value of applied deformation and annealing temperature. Figure 1b presents the microstructure with bimodal distributions of the grain size. The so-called columnar grains are located near to both samples surface while fine grained microstructure is concentrated in the middle. The average size of columnar grains, which growth to the center of samples is about $100 \mu \mathrm{m}$. This inhomogeneous microstructure was achieved after annealing of $6 \%$ deformed sample at $850{ }^{\circ} \mathrm{C}$ for 2 min in dry hydrogen atmosphere. The coercive force value of this sample was $\approx 105 \mathrm{~A} / \mathrm{m}$.

An example of columnar grains development in investigated steel is presented in Fig. 1c. This microstructure was achieved in the $2 \%$ cold rolled samples after laboratory annealing at $950{ }^{\circ} \mathrm{C}$ for $5 \mathrm{~min}$. As one can see, the investigated material is possessing quite homogeneous distribution of grains with average grain size $\approx 208 \mu \mathrm{m}$. The measured $H_{\mathrm{C}}$ value (around $18 \mathrm{~A} / \mathrm{m}$ ) shows that such microstructure provides the optimal magnetic properties of the steel.

The completely distinguished microstructure from the previous one was obtained in the investigated material taken after $10 \%$ of deformation and annealing at $950{ }^{\circ} \mathrm{C}$ during $5 \mathrm{~min}$. This microstructure is shown in Fig. 1d. It is well seen that the steel is characterized by homogeneous microstructure with average grain size $\approx 80 \mu \mathrm{m}$. It is necessary to note that in this case the average grain size has the dominant contribution into coercive force measure. A decrease of grain size increases the coercive force value up to $36 \mathrm{~A} / \mathrm{m}$.
The dependence of coercive force value on the mean grain size and applied deformation in the $\mathrm{F}$ steel is presented in Figs. 2a and b, respectively. Figure 2a presents dynamic change of $H_{\mathrm{C}}$ values versus mean grain size. It is well seen that the smallest values of the coercive forces were registered in samples with homogeneous and huge grained columnar microstructure. On the other hand, the EBSD analysis showed that the samples with columnar microstructure had domination of (100)[0vw] crystallographic texture. This texture is most favorable from final magnetic properties point of view. The curves behavior show the drastic decrease of $H_{\mathrm{C}}$ with increase of average grain size of experimental steel. The dependence of $H_{\mathrm{C}}$ value on applied deformation is presented in Fig. 2b. The comparison of the $H_{\mathrm{C}}$ behavior in Fig. 2a and b showed that the change of coercive force value is fixed by homogeneity and average grain size of microstructure. Thus optimally chosen annealing regime and deformation value can provide the best final microstructure for NO steels from magnetic properties point of view.

\section{Conclusions}

The work has shown the dependence of magnetic properties of non-oriented electrical steels on the peculiarity of microstructure. As it was shown the coercive force value is very sensitive on the change of average grain size and homogeneity of microstructure. In the case of bimodal grain size distribution, the coercive force value is more influenced by fraction of the fine grained matrix. In case of homogeneously microstructure the $H_{\mathrm{C}}$ value is controlled by average grain size. The smallest values of coercive forces were obtained for huge columnar grains.

\section{Acknowledgments}

This work was carried out within the frame of the project "Technology of preparation of electrotechnical steels possessing high permeability for high affectivity electromotors" ITMS 26220220037, financed through European Regional Development Fund.

\section{References}

[1] T. Shimazu, M. Shiozaki, K.J. Kawasaki, J. Magn. Magn. Mater. 133, 1471994.

[2] R.H. Heyer, D.E. McCabe, J.A. Elias, Flat Rolled Products, Interscience New York 1962, p. 29.

[3] L. Pinoy, K. Eloot, C. Standaert, S. Jacobs, J. Dilewijns, J. Phys. IV (France) 8, Pr-2, 487 (1998).

[4] O. Fisher, J. Schneider, J. Magn. Magn. Mater. 254-255, 302 (2003).

[5] A.J. Moses, J. Magn. Magn. Mater. 112, 150 (1992).

[6] Y. Sidor, F. Kovac, Mater. Character. 55, 1 (2005).

[7] Y.H. Sha, F. Zhang, S.C. Zhou, W. Pei, L. Zuo, J. Magn. Magn. Mater. 320, 393 (2008).

[8] B.D. Cullity, Introduction to Magnetic Material, Addison-Wesley Publ. Co., Reading, MA 1972, p. 287. 